\title{
Efficient syntheses of (-)-shikimate and (-)-quinate 3-phosphate via trans vicinal diol protection with 2,2,3,3-tetramethoxybutane (TMB) of shikimic and quinic acids
}

\author{
Tzenge-Lien Shih ${ }^{\mathrm{a}, *}$ and Shih-Hsiung $\mathrm{Wu}^{\mathrm{a}, \mathrm{b}, *}$ \\ anstitute of Biological Chemistry, Academia Sinica, NanKang 115, Taipei, Taiwan \\ ${ }^{\mathrm{b}}$ Institute of Biochemical Sciences, National Taiwan University, Taiwan
}

Received 23 December 1999; accepted 14 February 2000

\begin{abstract}
(-)-Shikimate 3-phosphate and (-)-quinate 3-phosphate can be synthesized by selective protection of their trans diol functionality using 2,2,3,3-tetramethoxybutane (TMB) using D-(-)-shikimic acid and D-(-)-quinic acid as starting materials. This versatile reagent facilitates the synthesis of these important biological targets in fewer steps than previously reported. By the proper choice of protecting group for C-3 hydroxyl in D-(-)-quinic acid, it can be converted to a key intermediate in the synthesis of (-)-shikimate 3-phosphate. (C) 2000 Elsevier Science Ltd. All rights reserved.
\end{abstract}

Keywords: shikimic acid; quinic acid; shikimate 3-phosphate; quinate 3-phosphate; 2,2,3,3-tetramethoxybutane.

The first chemical syntheses of (-)-shikimate 3-phosphate and (-)-quinate 3-phosphate were reported in $1992 .{ }^{1}$ Both of these syntheses required protection of the cis vicinal diols at C-3 and C-4 positions, respectively. This contributed to a long synthetic route.

2,2,3,3-Tetramethoxybutane (TMB) has been used in the protection of vicinal diequatorial diols in a series of carbocycles and carbohydrates. ${ }^{2}$ Furthermore, the TMB reagent has been used to convert (-)quinic acid into (-)-shikimic acid. ${ }^{3}$ These results prompted us to propose that the TMB could be used in the syntheses of both (-)-shikimate 3-phosphate and (-)-quinate 3-phosphate.

Our synthesis of (-)-shikimate-3-phosphate is described in Scheme 1. The trans vicinal diol of $\mathbf{1}^{1 \mathrm{a}, 4}$ was protected with TMB using the known procedure. ${ }^{2}$ However, we observed that the refluxing time affected the ratio of $\mathbf{2}$ and $\mathbf{3}$ in the product mixture. When the reaction time was $3 \mathrm{~h}$, compounds $\mathbf{2}$ and $\mathbf{3}^{5}$ were isolated in $75-85 \%$ yield in a ratio of 1.5:1. When the reaction was allowed to reflux for $18 \mathrm{~h}$, the mixture of compounds $\mathbf{2}$ and $\mathbf{3}$ was isolated in a ratio of 1:1.25. Prolonged reaction time (up to two days) provided $\mathbf{3}$ as the only isolated product in $77 \%$ yield. The C-3 position of $\mathbf{3}$ was phosphorylated ${ }^{6}$ to afford $\mathbf{4}^{7}$ in $72 \%$ yield. The one-step debenzylation and deprotection steps were accomplished simultaneously

\footnotetext{
* Corresponding authors.

0040-4039/00/\$ - see front matter (c) 2000 Elsevier Science Ltd. All rights reserved.

PII: S0040-4039(00)00280-X
} 
using bromotrimethylsilane in methylene chloride. Saponification and purification provides $\mathbf{5}$ in $\mathbf{7 6 \%}$ yield. ${ }^{1 \text { a }}$ Its ${ }^{1} \mathrm{H}$ NMR data is consistent with the reported value. ${ }^{1 \text { a }}$

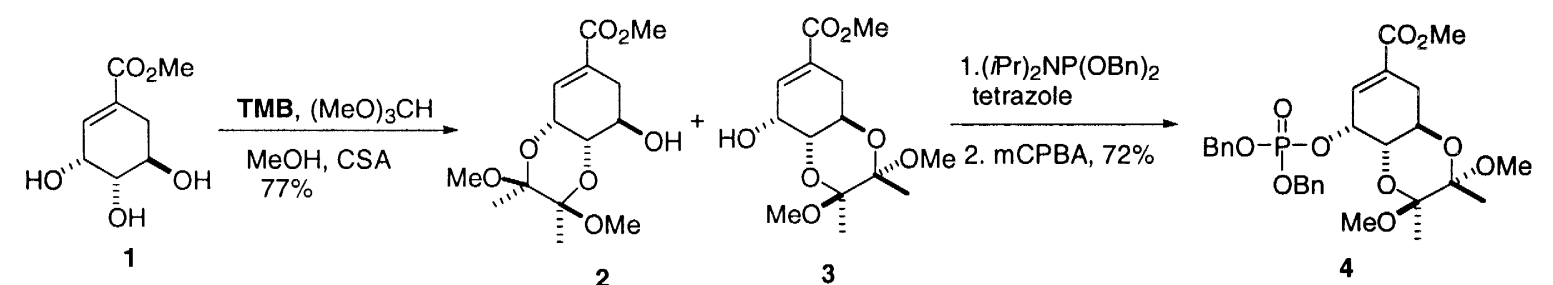<smiles>N#CC1=CC(OP(=O)(O)O[Na])C(O)C(O)C1</smiles>

Scheme 1.

The synthesis of (-)-quinate 3-phosphate is outlined in Scheme 2. The C-3 position of compound $\mathbf{6}^{2}$ was phosphorylated using the same procedure as described above, providing $7^{8}$ in $73 \%$ yield. Compound 7 was hydrogenated over $\mathrm{Pd} / \mathrm{C}$ (in $\mathrm{MeOH}$, rt, overnight) ${ }^{6}$ followed by acid hydrolysis (80\% TFA, rt, 4 h). ${ }^{2,3}$ The resulting syrup was subjected to a basic workup ( $\left.1 \mathrm{~N} \mathrm{NaOH}\right)$ to obtain $\mathbf{8}$ in $69 \%$ (three steps) after purification. Its ${ }^{1} \mathrm{H}$ NMR data is also consistent with the reported value. ${ }^{1 \text { a }}$

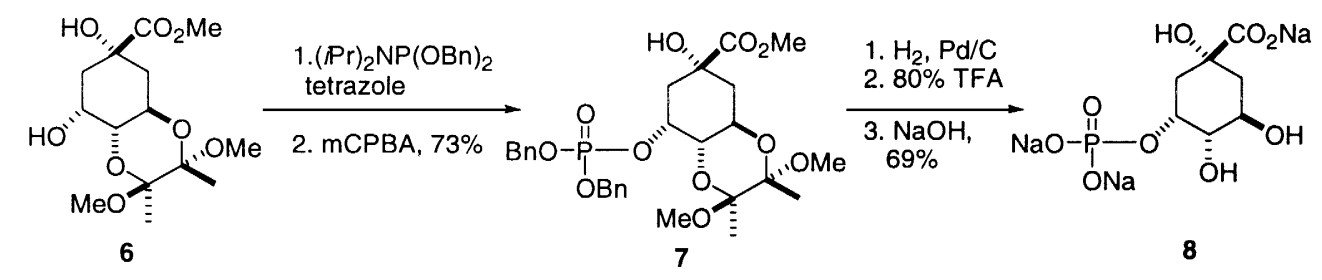

Scheme 2.

Some of our effort has focused on the syntheses of intermediates $\mathbf{4}$ and $\mathbf{1 0} 9$ from $\mathbf{7}$ and $\mathbf{9}$, respectively, using phosphorous oxychloride in pyridine ${ }^{10}$ (Scheme 3). Compounds $\mathbf{4}$ and $\mathbf{1 0}$ therefore served as precursors in the synthesis of (-)-shikimate 3-phosphate starting from (-)-quinic acid. In the examples of dehydration of $\mathbf{7}$ and $\mathbf{9}$, we observed that the elimination takes place exclusively opposite to the TMB protected diol, yielding $\mathbf{4}$ and $\mathbf{1 0}$ in 37 and $76 \%$ yields, respectively. The regioselectivity of double bond formation is consistent with that observed in the synthesis of D-(-)-shikimic acid from D-(-)-quinic acid. ${ }^{3 \mathrm{a}}$ However, the isolated yield (37\%) for $\mathbf{4}$ might be due to competing aromatization during the reaction since the phosphorous group may function as a leaving group. Indeed, a non-polar highly UVactive spot was observed by TLC which is not readily isolated by column chromatography. Furthermore, when the C-3 hydroxyl is protected with an acetyl group, the possibility of aromatization was eliminated, and a higher yield was obtained. The acetyl group of $\mathbf{1 0}$ can be further removed to prepare $\mathbf{3}$.

With this method, (-)-shikimate 3-phosphate and (-)-quinate 3-phosphate were obtained using the TMB reagent for the protection of trans vicinal diols in methyl-(-)-shikimate or methyl-(-)quinate, respectively. This route is more direct than previous routes to these important compounds. The regioselectivity of double bond formation in the dehydration of $\mathbf{7}$ and $\mathbf{9}$ can also be controlled by this trans diol protection. 


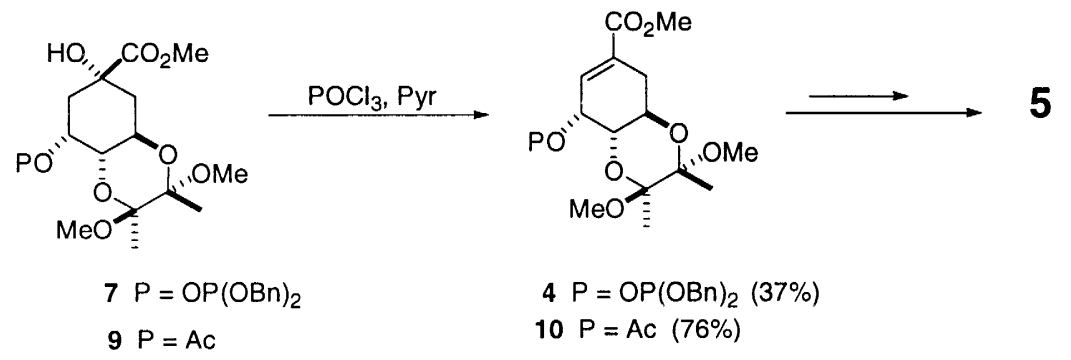

Scheme 3 .

\section{Acknowledgements}

T.-L. Shih gratefully acknowledges Academia Sinica for a postdoctoral fellowship. We also wish to thank Dr. C.-C. Lin at Academia Sinica for helpful discussions and Mr. Mark L. Micklatcher at Purdue University for proofreading this manuscript.

\section{References}

1. (a) Chahoua, L.; Baltas, M.; Gorrichon, L.; Tisnès, P.; Zedde, C. J. Org. Chem. 1992, 57, 5798. (b) For racemic synthesis of 3-phosphoshikimate acid, see: Bartlett, P. A.; McQuaid, L. A. J. Am. Chem. Soc. 1984, 106, 7854.

2. (a) Montchamp, J.-L.; Tian, F.; Hart, M. E.; Frost, J. W. J. Org. Chem. 1996, 61, 3897. (b) Douglas, N. L.; Ley, S. V.; Osborn, H. M. I.; Owen, D. R.; Priepke, H. W. M.; Warriner, S. L. Synlett 1996, 793.

3. (a) Shinada, T.; Yoshida, Y.; Ohfune, Y. Tetrahedron Lett. 1998, 39, 6027. (b) Alves, C.; Teresa Barros, M.; Maycock, C. D.; Rita Ventura, M. Tetrahedron 1999, 55, 8443. For natural product synthesis by using D-(-)-quinic acid, see review: Barco, A.; Benetti, S.; Risi, C. D.; Marchetti, P.; Pollini, G.; Zanirato, V. Tetrahedron: Asymmetry 1997, 8, 3515.

4. Shikimic acid, used for the preparation of $\mathbf{3}$, was purchased from Sigma.

5. The ${ }^{1} \mathrm{H}$ and ${ }^{13} \mathrm{C}$ NMR data are consistent with the reported values in Ref. $3 \mathrm{~b}$.

6. Yu, K.-L.; Fraser-Reid, B. Tetrahedron Lett. 1988, $29,979$.

7. Compound 4: pale yellow syrup. ${ }^{1} \mathrm{H} \mathrm{NMR}\left(\mathrm{CDCl}_{3}, 400 \mathrm{MHz}\right) \delta 7.25-7.39(\mathrm{~m}, 10 \mathrm{H}), 6.76(\mathrm{dd}, J=5.5,2.6 \mathrm{~Hz}, 1 \mathrm{H}), 5.13-5.23$ $(\mathrm{m}, 2 \mathrm{H}), 5.08-5.12(\mathrm{~m}, 1 \mathrm{H}), 5.00-5.06(\mathrm{~m}, 2 \mathrm{H}), 4.10(\mathrm{dt}, J=16.8,5.9 \mathrm{~Hz}, 1 \mathrm{H}), 3.74(\mathrm{~s}, 3 \mathrm{H}), 3.69$ (ddd, J=10.9, 4.0, 1.7 Hz, $1 \mathrm{H}), 3.23(\mathrm{~s}, 3 \mathrm{H}), 3.22$ (s, 3H), 2.83 (dd, $J=18.0,6.2 \mathrm{~Hz}, 1 \mathrm{H}), 2.25(\mathrm{ddd}, J=18.0,10.3,2.8 \mathrm{~Hz}, 1 \mathrm{H}), 1.27$ (s, 3H), 1.23 (s, $3 \mathrm{H}) .{ }^{13} \mathrm{C} \mathrm{NMR}\left(\mathrm{CDCl}_{3}, 100 \mathrm{MHz}\right) \delta 166.1,136.2,133.3,132.0,128.4,128.3,128.2,127.9,127.7,99.9,99.1,70.9,70.8$, $69.4(\times 2), 69.2(\times 2), 62.4,52.2,48.1,47.9,30.3,17.8,17.7$. LRMS $(\mathrm{m} / \mathrm{z}) 562.9\left(\mathrm{M}^{+}, 95 \%\right), 531.1\left(\mathrm{M}^{+}-\mathrm{OMe}, 100 \%\right)$.

8. Compound 7: white solid. Mp 103-105 ${ }^{\circ} \mathrm{C} .{ }^{1} \mathrm{H}$ NMR $\left(\mathrm{CDCl}_{3}, 400 \mathrm{MHz}\right) \delta 7.25-7.40(\mathrm{~m}, 10 \mathrm{H}), 5.17(\mathrm{t}, J=6.4 \mathrm{~Hz}, 2 \mathrm{H}), 5.08$ (dd, $J=7.6,4.3 \mathrm{~Hz}, 2 \mathrm{H}), 4.92$ (dd, $J=7.7,2.9 \mathrm{~Hz}, 1 \mathrm{H}), 4.36$ (ddd, $J=14.8,10.3,4.6 \mathrm{~Hz}, 1 \mathrm{H}), 3.75$ (s, 3H), 3.62 (dt, $J=10.3$, $2.6 \mathrm{~Hz}, 1 \mathrm{H}), 3.31$ (brs, 1H), $3.23(\mathrm{~s}, 3 \mathrm{H}), 3.19(\mathrm{~s}, 3 \mathrm{H}), 2.21(\mathrm{dt}, J=15.5,2.8 \mathrm{~Hz}, 1 \mathrm{H}), 1.98-2.12(\mathrm{~m}, 2 \mathrm{H}), 1.93(\mathrm{t}, J=13.0$ $\mathrm{Hz}, 1 \mathrm{H}), 1.25(\mathrm{~s}, 3 \mathrm{H}), 1.23(\mathrm{~s}, 3 \mathrm{H}) .{ }^{13} \mathrm{C} \mathrm{NMR}\left(\mathrm{CDCl}_{3}, 100 \mathrm{MHz}\right) \delta 175.0,136.3,136.0,128.5,128.4,128.3,128.1,127.8$,

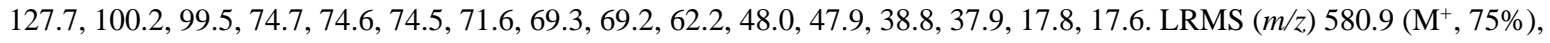
$549.1\left(\mathrm{M}^{+}-\mathrm{OMe}, 100 \%\right)$.

9. Compound 10: pale yellow syrup. ${ }^{1} \mathrm{H} \mathrm{NMR}\left(\mathrm{CDCl}_{3}, 400 \mathrm{MHz}\right) \delta 6.80(\mathrm{dd}, J=5.0,2.3 \mathrm{~Hz}, 1 \mathrm{H}), 5.53(\mathrm{t}, J=5.0 \mathrm{~Hz}, 1 \mathrm{H}), 4.07$ (dtd, $J=16.7,10.5,6.0 \mathrm{~Hz}, 1 \mathrm{H}), 3.74(\mathrm{~s}, 3 \mathrm{H}), 3.69$ (dd, $J=10.9,4.4 \mathrm{~Hz}, 1 \mathrm{H}), 3.25$ (s, 3H), 3.23 (s, 3H), 2.83 (dd, $J=17.9 \mathrm{~Hz}$, $6.0 \mathrm{~Hz}, 1 \mathrm{H}), 2.26$ (dddd, $J=17.9,10.4,2.8,0.9 \mathrm{~Hz}, 1 \mathrm{H}), 2.07$ (s, 3H), 1.28 (s, 3H), 1.25 (s, 3H), 1.23 (brs, $1 \mathrm{H}) .{ }^{13} \mathrm{C} \mathrm{NMR}$ $\left(\mathrm{CDCl}_{3}, 100 \mathrm{MHz}\right) \delta 170.4,166.3,133.3,132.2,99.7,99.1,68.8,66.1,62.9,52.2,48.0,47.9,30.0,20.9,17.8$, 17.6.

10. Ulibarri, G.; Nadler, W.; Skrydstrup, T.; Audrain, H.; Chiaroni, A.; Riche, C.; Grierson, D. S. J. Org. Chem. 1995, 60, 2753. 